\title{
Vulnerability under the gaze of robots: relations among humans and robots
}

\author{
Nicola Liberati ${ }^{1}$ (1) $\cdot$ Shoji Nagataki ${ }^{2}$
}

Received: 2 January 2018 / Accepted: 7 May 2018 / Published online: 14 May 2018

(c) The Author(s) 2018

\begin{abstract}
The problem of artificial intelligence and human being has always raised questions about possible interactions among them and possible effects yielded by the introduction of such un-human subject. Dreyfus deeply connects intelligence and body based on a phenomenological viewpoint. Thanks to his reading of Merleau-Ponty, he clearly stated that an intelligence must be embodied into a body to function. According to his suggestion, any AI designed to be human-like is doom to failure if there is no tight bound with a human-like body. Today, we are facing the pervasive introduction of robots into our everyday life, and the problem of this co-existence raises again with new vigor since they are not mere speculations, but there are already products sold to the public. We will highlight how vulnerability has to be taken into consideration in the design of robots to create entities which are able to relate to human beings taking into consideration mainly the positions of Sartre, Habermas, Levinas, and Marleau-Ponty. A first part will focus on the vulnerability of the robots. Robots are going to be among us, but a real interaction is possible only the moment they have a "same" body of ours. Therefore, only through the realization of a "fragile" body we can achieve a cohabitation between equals. Thanks to Merleau-Ponty we will show how the vulnerability of a body is one of the most important element to found any social interaction. The second part will focus on how the robots will affect the vulnerability of the human subjects. To produce vulnerable robots is not a mere neutral introduction, but it shapes how the subjects are constituted. Thanks to Levinas, we will study how the vulnerable robots will shape the subjects. Thanks to Sartre, we will show how the creation of a different gaze in the robot changes the vulnerabilities of the human subjects. Introducing vulnerable robots is a way to shape ourselves.
\end{abstract}

Keywords Vulnerability $\cdot$ Robotics $\cdot$ Otherness $\cdot$ Alterity $\cdot$ Agent $\cdot$ Mediation theory $\cdot$ Phenomenology

\section{Introduction}

Human ancestors have survived a narrow pathway of evolution. Smaller residence brought about by a climate change and drastically reduced tropical rainforest might have kicked them out of their homelands. Or they might have had "the misfortune to be living at the margins of the forest" (Lieberman 2013, p. 48) and have been influenced by the climate change directly. Our ancestors were vulnerable in their origin.

Nicola Liberati

liberati.nicola@gmail.com

Shoji Nagataki

shojinagataki@gmail.com

1 Department of Philosophy, University of Twente, Enschede, Netherlands

2 Department of International Liberal Studies, Chukyo University, Nagoya, Japan
In the following section, we consider the history of humans in terms of struggles for overcoming vulnerability and situate contemporary technologies advanced through agricultural, scientific and industrial revolutions on the background of those struggles. Then, in Sect. 3, we analyze what possible products of robotics mean to us from a viewpoint of vulnerability, with a special attention to the problem of robot-human coexistence thanks to the use of Habermas and Merleau-Ponty.

In Sects. 4 and 5, we will take into consideration what the introduction of vulnerable robots will mean for us. Especially, we will analyze how our constitution as human subjects are shaped by the introduction of new vulnerabilities and new vulnerable entities thanks to the use of Levinas and Sartre. This work will not be a general analysis on the idea of vulnerability in phenomenology to better clarify its importance within philosophy, but our analysis will focus on the effects the introduction of vulnerability will have on the subjects in the case of robots. Therefore, it will be an analysis oriented mainly 
towards the introduction of this theme into robotics more than a phenomenological analysis on vulnerability per se.

\section{Taming nature and vulnerability}

\subsection{Taming nature}

The vulnerability specific of humans has profoundly shaped their history, which goes back to the ages when they started their lives in Savanna. It is also a history of striving for reducing dangers in nature and overcoming their vulnerability. Humans used to be so vulnerable and are often still so (Kruuk 2002, p. 53). For example, "no person alive could possibly match" his relative, "a chimp, for speed, power, and agility" (Lieberman 2013, p. 31). They had to protect themselves from their predators before they could be big game hunters. Compared with tropical rainforests, Savannas are more "open and risky habitats" (Lieberman 2013, p. 55), so they had to blush up their ability to cooperate with each other. According to Hart and Sussman, "predation pressure was one of the major catalysts for the evolution of humankind" (Hart and Sussman 2005, p. 247). Put simply, we have evolved while having been hunted. The ability to cooperate with each other made it possible for our ancestors to hunt big game animals. However, it was still no easy task for them to obtain food even in the life of hunting and gathering; being cooperative and sharing games could alleviate the risk of starvation.

In the history of coping with vulnerability, the agricultural revolution, in which the cultivation of plants and domestication of animals began, enabled the stable supply of food and boosted the population increase. "[I]f infant mortality rates were as high among farmers as they were among foragers [hunter-gatherers], early farming populations would have had twice the rate of population growth" (Lieberman 2013 , p. 203). Improvement in nutrition supply had an enormous effect on prolonging the life span of humans.

The scientific and the industrial revolutions marked another two major watersheds. Before these greatest changes, nature was sometimes represented as mysterious, unintelligible, even awesome for us. The empirical knowledge of natural sciences has transformed it into something "wholly intelligible and nothing unpredictable" (Shapin 1998, p. 36). Now nature became controllable to a certain extent.

They [modern experimental sciences] combined the objectivating attitude of the disinterested observer with the technical attitude of an intervening actor producing experimental effects. ... This gearing of science to the task of converting an objectivated nature into something we may control by technological means had an important impact on the process of societal modernization. (Habermas 2003, p. 45)
The application of natural sciences made it possible to supply more nutritious foods and succeeded in explicating and overcoming diseases that had been deemed incurable. On the other hand, science and technology have given humans the power to alter and even destroy nature itself on a different scale from before. For example, the progress of desertification by large-scale deforestation brought about the irreversible transformation of the environment. They have also brought us new types of risks that have never been before. The ingestion of much starch after the agricultural revolution brought us cavities, which were "rare among hunter-gatherers but extremely common in early farmers" (Lieberman 2013, p. 209). The growth of food production and the changes in the quality of work life after the industrial revolution were posing problems as well. They brought us mismatch diseases "such as type 2 diabetes and heart disease" (Lieberman 2013, p. 269) caused by a poor balance between the amount of eating and that of energy consumption. Mismatch diseases are "defined as diseases that result from our Paleolithic bodies being poorly or inadequately adapted to certain modern behaviors and conditions" (Lieberman 2013, p. 182). We can call those risks a new type of vulnerability due to the development of science and technology.

\subsection{Facing new type of risks}

Humans have devised a variety of tools and changed their environmental world to compensate for their vulnerabilities. As a result, while old types of risk, such as shortage of food, menace of predators and so on, have been substantially reduced, new ones have emerged. For example, various machines developed after the Industrial Revolution helped to relieve us, even though partially, of harsh manual labor. However, they have transformed the form of labor and work environment, which is conducive to the mismatch diseases mentioned above. This is also illustrated by the fact that the use of X-rays aiming at the early detection of lesions might in turn cause new lesions, and that those with pacemakers and ICDs implanted have to avoid electromagnetic and, in some cases, high-frequency waves. There are new forms of vulnerability which have never been before.

[N]ew technologies ... always create new risks and vulnerabilities, thus transforming human vulnerability rather than substantially reducing it. (Coeckelbergh $2013,12: 5)$

We can view the current development of $\mathrm{AI}$ and robotics from a historical perspective of coping with human vulnerability. It has reduced the burden of vast calculation and precise work that are troublesome for humans. (This does not mean that tasks on which human intelligence focuses have substantially reduced. Rather, they have been transformed so that more advanced work has been placed upon us.) Just as 
considerable part of physical labor has been taken over by machines since the Industrial Revolution, more and more part of intellectual labor is being transferred to them since the latter half of the twentieth century. Some people respond as modern Luddites, having fear that human labor would be negatively affected by the newcomers. This situation is also, though not very serious, a manifestation of human vulnerability.

According to Cartesian ontology, products of scientific technology, no matter how excellent they are, belong to res extensa, thus essentially different from humans in a metaphysical sense. In the near future, robotics and AI research may succeed in creating very humanlike beings which can exceed human intelligence in a certain sense. ${ }^{1}$ The human desire to replicate themselves may make such beings more than just industrial products, just res extensa. Those beings, which are a kind of externalization of human intelligence, could become res cogitans like us in the sense of beings with mind and consciousness. We might even notice within us "the archaic remnants of emotions which may linger in our revulsion" (Habermas 2003, p. 25) against such beings. In that case, we will have a much more crucial problem of whether we should accept such intelligent and humanlike robots as our partners.

What is necessary for such robots to be accepted as social members for us, or to coexist with us ${ }^{2}$ How can they be not just mere objects, but intersubjective beings which can

\footnotetext{
${ }_{1}^{1}$ Robots can be introduced in our society as the following studies suggest (Kanda et al. 2009; Wada and Shibata 2018; Foster et al. 2016; Aaltonen et al. 2017; Liberati 2018).

${ }^{2}$ Some people think that it is of particular importance for robots to have similar appearance with humans in order for them to be accepted as social members. Such human-like robots have appeared recurrently in many novels and movies. Notably worth mentioning would be a development of humanoids in Japan. However, a Japanese engineer proposed a noteworthy view on the very similarity between them more than 40 years ago. He wrote:

I have noticed that, as robots appear more humanlike, our sense of their familiarity increases until we come to a valley. I call this relation the "uncanny valley." (Mori 1970, p. 33).

The "uncanny valley" is the point where our sense of familiarity with robots is allegedly fails suddenly. Much discussion has been made about its implications, especially in Japan, and several ideas have been proposed as orientations for proceeding with the study. Put roughly, there are two general approaches to the study of humanoid robotics: one focusing on appearance and behavior, putting much weight on mimicking those of humans, the other on explicating and reproducing our "inner" cognitive functions. The former tries to further realizing as much human-like appearance as possible, assuming that the alleged valley does not pose, in fact, any serious obstacles. We can name, among others, Dr. Ishiguro, whose meticulous construction of Repliee Q1 and Geminoid (Becker-Asano 2011) are well known. The latter takes note of the remark made by Mori in a more sincere manner, and tries to get over the "valley" by implementing functions similar to a human mind. Nagataki et al. (2013) can be identified with this orientation. It should be noted, however, that these two approaches are not exclusive at all. In fact, they can complement and interact with each other in a fruitful way. In the present paper, I will elaborate this in some detail.
}

share with us "processes of reaching understanding and self-understanding" (Habermas 2003, p. 10)? My thesis is that they have to be a moral agent with a kind of humanity. Otherwise, such robots can be a new type of significant risk for us.

\section{Robot as moral agent}

What kind of beings do humans accept as moral agents? Analyzing situations in which someone is deemed a moral agent, there are, among others, two conditions to be met. First, it can be seen as being basically similar with each other in terms of bodily structure, cognitive ability, and so on. Second, despite those similarities, there is a variety of differences in each individual, some of which are inscrutable from the first-person perspective. Third, morality can be acquired only if we are mindful of our vulnerability and social dependence. Habermas writes in a thought-provoking way:

Moral rules are fragile constructions protecting both the physis from bodily injuries and the person from inner or symbolical injuries. (Habermas 2003, p. 33f).

In the following, we would like to elucidate relevant similarities and differences with taking human vulnerability into consideration.

\subsection{Embodiment and psychological abilities}

Psychological abilities specific to humans are bodily restricted. Our cognitive style is largely determined by physical features that we have. For example, the perceptual world appears in a perspectival way due to the bodily constraints. In spite of, or rather because of this perspectivality, our cognitive ability or intelligence functions in such a way as to extend a limited range of information. In addition, human cognition is not based on symbol processing separated from the environmental world, but on bodily interaction with and cognitive adaptation to it. Put another way, we generally use affordances according to specific purposes. As a matter of fact, our vulnerability emerges from such relationship; foods afford eating, which can sometimes be harmful. A cliff affords our walking along it, involving the possibility of falling off and getting injured (Gibson 1979, p. 137).

Various individuals are also included in our perceptual world. When communicating and interacting with them, the condition that a physical isomorphism holds between us is of great importance. Whether the other is a human or a human-like robot, clues to properly capture its intention are provided by our having similar bodies. Such similarity helps us to predict how it perceives the outer world and what intent it has. 
The ability of joint attention that human children acquire in their early stage of development is a representative example to use the bodily similarity. Both the mother and the young child understand, with gazes as a clue, what each other is seeing. This can be possible because the bodies and their usage are basically similar so that they can use the line of sight as a clue to detect the direction of attention. This fact suggests that a similar bodily structure and psychological abilities are necessary for a robot to be a moral agent.

\subsection{Bodily similarity and ontological homogeneity ${ }^{3}$}

As developmental psychologists have shown, even a newborn child can understand the basic meanings of others' expressions through a primitive body scheme. Understanding facial expressions is one type of imitative behavior with an implicit intention, and as such very primitive. Of course, it would be possible to give an evolutionary explanation to this kind of psychological ability: it was favored by natural selection.

From a phenomenological point of view, this kind of psychological ability is based on bodily similarity and ontological homogeneity among us. The similarity makes it possible for us to intuitively comprehend, for example, the ways how organs such as eyes and a mouth function. It also enables us to recognize our relationship with things in general. "People use this pipe to smoke cigarettes, use this spoon to eat, use this bell to call someone" (Merleau-Ponty 1945, p. 400). Because of the constitutional similarity of the body, we can understand these things beyond cultural differences immediately. In their recent book, Dreyfus and Taylor write;

Our first level [of communication] is the universally human, and is closely linked with our similarity as organic beings-in certain cases, even with what we share with the animals.(Dreyfus and Taylor 2015, p. 107)

\footnotetext{
3 A brief mention to a therapy robot named Paro (Bemelmans et al. 2015) would be appropriate here. Paro, which looks like a seal, was developed under the inspiration of animal therapy and has been introduced into elderly facilities in Japan and some European countries. It is covered with soft body hair and can make a weak cry. Though it does not engage in verbal interaction, elderly people can have a sense of direct interaction by hugging and stroking it. In fact, they sometimes regard it as a vulnerable being worth caring and even cherish it. What is important is that this therapy robot appeals to our tactile sensations, inducing a rather strong familiarity in them. This can lead to reducing the stress of elderly people as well as that of nursing and medical staff. Paro can make people feel a kind of affinity with it, so that they treat it as if it were a moral subject, if not a moral agent. This robot draws on an integral feature of human nature in which touching the partner can provoke a certain kind of moral sympathy for her.
}

Along with the similarity, it is what Merleau-Ponty calls the original "peaceful coexistence" (Merleau-Ponty 1945, p. 408) that gives a basis for mutual understanding between oneself and others: a relationship holding on a "common ground" of consciousness, or the intersubjective world of perception.

Merleau-Ponty writes that humans have "the primordial contract" (Merleau-Ponty 1945, p. 253) with this perceptual world. It is the event which provides their infrastructure and which is their birth (Merleau-Ponty 1945, p. 517). Why you can see things and touch them? It is because the perceptual world, things in it, and humans are made from the same qualitative elements. "[T] he primordial intersubjectivity" (Zahavi 1999, p. 171) has always already been established between myself and others by our participating in the world. Self and others have reached a fundamental mutual understanding tacitly and preconsciously on the basis of the ontological homogeneity with Mother Nature - that is, what "makes us simultaneous with others ... in the most private realm of our life" (Merleau-Ponty 1968, p. 24). Dreyfus and Taylor put it in a different, but related way. "We can always count on instant communication around our nature as bodily agents, and the shared life needs..." (Dreyfus and Taylor 2015, p. 112). ${ }^{4}$

\subsection{Skin, vulnerability, and humanity}

Humans can be subject to pain, illness, injury, disability, and death. They can feel pleasure as well. There is "a common human vulnerability" (Butler 2004, p. 31), which is specific to us, beings with the body. Butler wrote that "we cannot think the ontology of the body without the body being somewhere, without some "thereness"' (Butler 2009, p. 53, note 12 ).

Injuries and diseases are caused when the skin and inner tissues are physically damaged, when ultraviolet rays erode the skin, or when bacteria, viruses, or toxic substances affect the body through the skin-boundary. Even the diseases occurring inside the body are basically caused by events outside the skin. No matter how science and technology progress, our vulnerability comes down to the fact that the skin is thin and susceptible to damage. As Coeckerlbergh says, "we have to realize that we are existentially vulnerable and that we are naked." (Coeckelbergh 2013, 12:43).

\footnotetext{
${ }^{4}$ Relying on Gadamer's conception of "fusing horizons," they criticize Davidson's argument concerning "principle of charity" as "epistemological" (Dreyfus and Taylor 2015, p. 111). Davidson's argument implies "[t]he disturbing possibility" that two societies or cultures "may never be able to understand each other, may remain forever locked inside their own ways of sense-making" (Dreyfus and Taylor 2015, p. 111)
} 
The direct and mutual relationship between humans and the world and things in it is sometime expressed by a metaphor of touching. "It is necessary that between exploration and what it teaches me, between my movements and what I touch, there exists some relationship of principle, some kinship, according to which they are ... initiation and openness to a tactile world" (Merleau-Ponty 1964, p. 175). Seeing is strongly linked with touching to express that vision is a direct relationship with things. Vision is the palpation of the eye (Merleau-Ponty 1964, p. 175).

Merleau-Ponty goes even further to say that our body is made of the same "quale" or "tissue" as the world, or the nature, and things in it (Merleau-Ponty 1964, pp. 175, 302, 309). So, if he is justified in saying that, the world is also vulnerable as humans are. This leads to the view that the world can be susceptible to an excessive force that science and technology brought about. Admitting that the world is Mother Nature and a common basis among us would put us into an embarrassing situation. The excessive force of science and technology might commit parenticide.

However, it is not only the human world that has become incomprehensible, but also nature itself nearly explodes. Technology and science confront us with energies which are not in the framework of the world, which could possibly destroy it, and possess means of exploration which, even before they have been employed, awaken the old desire and the old fear of encountering the absolute Other. (MerleauPonty 1968, p. 145).

The "absolute Other" which Merleau-Ponty says here is neither a poor, a master, nor God in Levinas's sense, but the being which can be evil for us: the one which completely lacks humanity. If robots and AIs produced by scientific technologies in the twenty-first century do not share the common ground with us and the world in some way, they cannot be moral agents.

\subsection{Alterity, irreplaceability, and machine as a moral agent}

The discussions so far suggest the importance of bodily similarity and ontological homogeneity with us. (Of course, it is extremely difficult for machines like robots to satisfy these conditions at the current moment.) However, these do not suffice for something's being a moral agent. There is another element to be considered: alterity, or otherness, against such affinities.

Alterity means an irreplaceability in some essential respect. To be a moral agent is to bear its own responsibility which others cannot take for it. My thesis is that such an irreplaceability consists in its having a rich inner world. The personhood of a moral agent, which is irreducible to a mere difference of trait or feature of individuals, is firmly rooted in such an inner world.
The irreplaceability can be viewed along another dimension; it is related to the problem of whether a first-person perspective can be attributed to the other in question. This kind of perspective involves a private realm to which other people cannot have direct access, and which provides one reason for us to treat something as the other and to accept it as a moral agent. Such private realm is where our personality and irreplaceability, including that of moral responsibility, lie in. On Merleau-Pontian conception, such a realm is based on the ontological common ground.

Habermas makes much the same point when he talks of "the morally relevant limit to instrumentalization" of other people. He discusses genetic intervention in humans, arguing that the limit "is set by what, in the second person, will be out of my reach" (Habermas 2003, p. 55). This out-ofreach-ness, which resonates with Levinasian thought, is an essential element that constitutes rich inner-world of others.

Thus, for example, a machine which functions in a predictable or required way does not have its "alterity," even if it is as good an industrial product as can be. When coordinating ourselves to engage in a cooperative activity, we will feel an affinity between us, while when failing in it, a sense of alterity, impenetrability, or inscrutability will be imposed upon us.

In fact, such alterity is very familiar. It is a common experience that we find similarities as well as differences between us. Suppose that you and I agree to have lunch together, but you force me to eat something I have not expected in a restaurant. In that situation, I would feel I have lost my initiative. This happens in our everyday life. We have a sense of alterity in unexpected transfers of initiative. However, this process can also cultivate our relationship and help us to reconfirm the common basis between us.

As we discussed in Sect. 3.4, humans have their own inner states which are inscrutable to each other. This aspect is, in relatively large part, realized by psychological abilities specific to humans. Alterity and morality are based on the irreplaceability of us, which is closely related with such an inscrutable inner affluence. If we can implement this affluence in robots, we might regard them as moral agents in some way. If the results from the experiments introduced in Sect. 5 will be as expected, there would be some empirical underpinning for our thesis.

As we have argued in Sect. 3.3, the ontological homogeneity with us is needed for something to be a moral agent. This homogeneity can be grasped by the concept of, for example, vulnerability characteristic of us. It seems impossible to realize this property in machines at the current moment. We are uncertain whether it is just a technological problem of bio-engineering or a deeper metaphysical problem. 


\section{Vulnerability and gaze in Sartre and Levinas}

As we showed, the introduction of vulnerability into the robot is one of the main element to change our relation with them. Therefore, the ontological status of these robots among us directly depends on how we design them, and the way they are perceived by the human subjects directly relates to specific features embedded in them.

This direct introduction does not merely affect the robots and their way of being perceived by the people around, but it has effects also on the way these people think of themselves and the way they think of their vulnerability. By producing vulnerable robots, the society actually shapes what means to be vulnerable and how they are constituted as human beings. Thus, we will show it possible to see the introduction of vulnerability in the robots not as a mere improvement in what the robots are, but also as a way to shape ourselves through them.

To show this modification, we will take into account the encounter of the other in Levinas and the effect of others' gaze in Sartre. Thanks to these two philosophers, it will be clear how the introduction of vulnerability in the robots has direct effects on the constitution of the subjects.

\subsection{The "other" in phenomenology}

The theme of the "other" is one of the most important themes in phenomenology.

In Husserl, the subject is always immersed into an intersubjective world. The actions, and motivations of the subject are always deeply intertwined with the ones of others. The subject is not alone, and the subject perceives others around them through empathy and the perception of their physical body.

Obviously, in Husserl, perceiving subject and intersubjectivity are deeply intertwined since intersubjectivity founds objectivity thanks to mutual understanding and the possibility of trading places (Duranti 2010; McGee and Warms 2013, p. 420; Husserl 1989, III:177, 1983, II:125). Objectivity is founded on the presence of others which make our perception not solipsistically founded, but grounded on intersubjectivity.

However, even if the others are taken into consideration as part of the intersubjectivity (Husserl 1973), we do not have an accent on the presence of the others around the acting subject as in the case of other phenomenologists. Husserl focused on empathy and on the experience of the other through the eyes of the perceiver (Hermberg 2006, p. 49). The other is perceived as another subject in the world starting from the presence of their body as perceptual objects. Some of his scholars such as Levinas and Sartre criticize this point of view because by allowing the other to be relevant starting from his presence in the world as a perceptual object, we risk losing some of its peculiarities.

The other is not merely an object of perception, but it calls for a completely different approach which tackles themes like vulnerability.

\subsection{Levinas}

According to Levinas, the other is not merely an object of perception, but when the subject encounters an other, the subject faces its vulnerability, and this mere exposure of others' vulnerability has deep effects on its constitution.

The face of the other is something more than a mere object of perception. Facing the other is facing something which needs care and help. ${ }^{5}$ The simple presence of something outside of the subjects' freedom demanding help makes the subject perceive other's vulnerability and nakedness (Levinas 1987, 100:55). ${ }^{6}$

This encounter with the vulnerability of the other is the moment where the relation with the other becomes ethical. Therefore, the other is not something which is merely a perceived object, but it is exposed to us, and this vulnerability founds the perceiving subject as something more than mere acting subject by allowing him/her to care about the other. Thus, this encounter opens the subject to ethics. ${ }^{7}$ As Levinas always highlights, the other is not merely an object perceived in the world, but it is part of the primordial constitution of the subject since it generates the subject as an ethical subject who cares of the others (Altez 2007).

The "others" are part of the constitution of the subjects since they shape who the subjects are by working on the others' vulnerability exposed in the encounter.

\footnotetext{
5 "For Levinas, the "face" is precisely that which radically and infinitely exceeds the "countenance," not as inaccessible but as exceptionally vulnerable." (Burggraeve 1999, p. 43).

6 "Levinas will surely agree that to be moved by another person's pain means to be shaken by his pain, that his vulnerability in some sense reveals one's own vulnerability." (Nortvedt 2003, p. 226).

7 "As Levinas develops his model, it becomes clear that his notion of vulnerability is one which will answer to my own use of the term to mark a state which is as much that of the one as of the other. Although initially it is the other who is vulnerable, who is figured as homeless, poor, widowed, orphaned, and whose suffering humanity invokes response, that response itself-or rather the irrestistibility of the call-pitches me also into vulnerability. I am exposed before the nakedness of the face, the certainty of my own existence thrown into doubt. It is my moral subjection to the other, my vulnerability in exposure to her vulnerability, that instantiates me as a subject. At the level of my corporeity, of my incarnation 'before being tied to my body', the relation with the other-before any conscious determination-is characterised by Levinas as maternal" (Shildrick 2002, p. 92).
} 


\subsection{Sartre}

In the case of Sartre, we have a different approach towards the encounter with the other (Jopling 1993). Even according to him, the encounter with the other is something more than what highlighted by Husserl. The other constitutes who the subject is at a different level.

However, Sartre does not follow the same path of Levinas, and he shows how the other constitutes the subjects not because the subject looks at the other, but because the other looks at the subject. Therefore, the accent does not fall on the subject who perceives and encounters the face of the other, but the point of view of this encounter is inverted. The other is not an alterity encountered by the subject, but the other acts on the subject in this encounter. The others are not objects of the subjects' perception, but they make the subjects objects of their perception.

Especially Sartre highlights how the other always looks at the perceiving subject, and he takes this element into the constitution of the subject (Dolezal 2017). The other perceives the subject and so it turns it from an active entity into a mere object of perception. Therefore, the other is not merely another entity which helps to constitute the objectivity of our world as Husserl suggested. The other is not even merely something different from an object because it is vulnerable and it triggers ethical actions in the subject as shown by Levinas.

The other, according to Sartre, has the power to make the subject feel powerless because the subject becomes a mere object for the other. The subjects perceive themselves through the eyes of the other, and so they objectivize ourselves. Therefore, the presence of the other has the power to change the perspective of the subject (Sartre 2001; Zahavi 2011, 2014).

The encounter with another person is not conjectural, but it is actual. The person can feel shame through this change of perspective because the subjects perceive how the other perceives them. The subject is powerless in front of the gaze of the others. It is vulnerable because its body and its actions are exposed to the others' gaze as objects of their perception.

There is an inversion of power relations. With objects, the subjects direct their gaze towards them. With others, the situation the opposite, and the subjects find themselves under the gaze of someone else. The subjects' body is not merely a private body, but others look at it. Subjects are perceived as objects from other people, and, through this objectification from their point of view, subjects become vulnerable and exposed. ${ }^{8}$

\footnotetext{
8 "In Sartre, the other's look is not defenseless and exposed; rather, I am exposed and vulnerable when I am subjected to the other's look." (Overgaard 2013, p. 115).
}

Subjects are constituted through the presence of others since they are open and vulnerable entities. Subjects feel shame and pride just because they are open to others, and their body is the center of this shameful feeling because it is what is vulnerable and open to the others' gaze.

The other is not merely encountered because it is in the world like other objects, but the other has peculiar effect on the constitution of the subject just because it looks back, and it objectifies the subject. Subjects are "naked" in front of the other just because subjects encounter another person who is objectifying them, and subjects have no power at all on this objectification.

\subsection{Constitution through vulnerability}

As we showed, according to Levinas and Sartre the presence of the others deeply affects the constitution of the subject (Sealey 2013). Especially the others in their vulnerability turn the subject into an ethical subject and the presence of the gaze of others turns the subject into a vulnerable being.

Thus, we have a two elements highlighted by the introduction of the other. The subject feels ashamed by looking at the vulnerability of the other. The others are vulnerable in their own nakedness and this vulnerability affects us.

At the same time, the subject is turned into a mere object through the gaze of others, and so the subject itself is turned into a vulnerable entity by the introduction of the others.

\section{Robots and vulnerability}

The idea of otherness related to the phenomenological tradition and robots is not new (Sandry 2015). However, many aspects related to the vulnerability and the constitution of the subject which are relevant to our theme are often excluded.

As we showed the introduction of an "other" entity in the world is not neutral, but it shapes the way the subject is constituted, and the vulnerability is one of the main element founding this modification. Therefore, the introduction of different kind of others which are vulnerable in different ways and which have different perceptual capabilities like robots have an impact even on the constitution of the subject. The introduction of new vulnerable robots is not merely an introduction of a new entity, but through this introduction subjects shape themselves.

\subsection{Different vulnerability in the robots}

The introduction of a vulnerable entity has effects in the way we feel our vulnerability, and so it affects also how the subjects are constituted in their vulnerability.

As we have shown, Levinas clearly highlights how the perception of the vulnerability of the other transforms the 
subject into an ethical being. The perception of the fact there is an entity needing help is more than enough to turn the subject into something different.

The difference in the vulnerability of the robot and the human being is related to the kind of body they have. They are different, and so they have also different vulnerabilities (Coeckelbergh 2011). Both of them have needs, but the nature of these needs can vary sensibly. For example, one needs to be fed of bread and the other one has to fed with electricity.

Obviously, Levinas never introduced the face of the other as related to the physical body of the other (Levinas 1988; Atterton 2011; Davy 2007; Guenther 2007). The face is introduced to highlight a relation between the subject and the other without focusing on any kind of physical element. Therefore, by eluding any physical relation to the physical body of the other, the face of the other does not change if the other is a human being or another entity with a different body like a robot. However, at the same time, there is a clear link to the vulnerability of the other which is directly related to the others' needs. If the other suffers or is needing a help, the subject is called to act. Therefore, this call for help changes according to the different needs and different vulnerabilities exposed in the other. Even if the general call for help does not relate specifically to their actual body, the different actions moved by the face of the other directly depends on the actual body of the other exposing their vulnerabilities.

For example, the Sociable Trash Robot developed by Toyohashi University clearly highlights the relation between users and robots according to the specific vulnerability of the robots (Yamaji et al. 2010). The robots are supposed to pick up trash, but they are not able to act merely on their own. Since it is possible to visualize this limit of the robot as a kind of vulnerability which stimulates the subject to help them in their task, the subjects are called to help them and to pick up the trash. Therefore, even if it is just an example, it is clear how the vulnerability of the robot is not merely something designed and introduced into the world, but it has effects on the subjects too by making them face new vulnerabilities and act accordingly. The social trash robot is vulnerable, and it asks for help. This mere vulnerability introduced into the robot actually has a direct effect on the subjects who are moved to help them in their task to clean the area from trash, and so it opens the subject to modify their values accordingly to the value of the robots. Even in the case the subject did not see the trash as something to be taken away, once the robot, in its struggle to pick up the trash is introduced, the subject is moved to help it, and so the trash becomes something to be taken away. Obviously, this is just an example, but it shows how the subject is shaped by the introduction of a new vulnerability in a robot.
The way the vulnerability of the other is perceived changes according to the kind of entity the subject is facing and so, with it, it changes also the ethical call involved.

\subsection{Robots and their different gaze}

The other effect we have with the introduction of the other into the constitution of the subject is related to the others' gaze on the subject. We showed, how, according to Sartre, the gaze of the others changes the subject by turning it into something vulnerable.

The simple presence of the other turns the subject into something which is open to the others and this openness is what makes it vulnerable.

Sartre, as Levinas, never talks about actual others in relation to their physical appearances. The subject is objectified, exposed and vulnerable because of the very presence of others without relating to any specific elements of the others' body. Therefore, this opening is not related to how the others perceive the subject, but merely on the possibility of the presence of others in general. However, it is possible to relate this gaze to the actual perceptual capabilities of the otherness who is observing the subject.

The body of the subject becomes object of the perception of the other, and so the way the other is able to perceive the subject affect the way the objectification is performed. Subjects are under the gaze of the other, and depending on what kind of gaze the other have, some aspect of the subjects are visible or not.

The simple fact a robot can have different sensors which make visible to them hidden aspect of human subjects makes them open in different ways, and so their vulnerability is modified accordingly. For example, if the eyes of the robot are composed of a camera which is able to detect thermal infrared radiations, the robot is able to detect emotions like the sexual arousal of a person (Kukkonen et al. 2007; Kukkonen 2015; Ioannou et al. 2014; Hahn et al. 2012; Cardone et al. 2015). Therefore, these robots can perceive something which was hidden before like the emotions of the human subjects. This is enough to generate a different vulnerability in the subject since now the gaze reaches different aspects of themselves. Because the robots can perceive in a different way, human subjects are naked in other aspects. ${ }^{9}$

This new opening modifies what the human subject is since it touches its vulnerability and how the subject feels exposed and objectified by others.

\footnotetext{
${ }^{9}$ For example, a robot able to detect the emotions (Liu et al. 2017) of the users make the users is able to detect what other human beings maybe cannot. Therefore, the users are exposed to the gaze of the robot in a different way because their emotions are not private anymore, and their vulnerability is shaped accordingly.
} 


\section{Conclusions}

The world could be a ruthless, amoral arena, without understanding the fact we are essentially vulnerable. The ability of imagination helps us to recognize vulnerability in others, even in many kinds of organisms. What about the intelligent entities we are trying to create?

For robots to be mere instruments, it would be sufficient that they were controllable, break-proof, and robust. More would be needed, however, if some entities are to be regarded and accommodated in our society as beings with some kind of personhood and intelligence. To achieve such result, psychological and physical vulnerabilities play essential part of it.

Moreover, the introduction of vulnerability into robots is not a mere neutral introduction which turns robots into something more than mere tools. This introduction touches directly the constitution of the human subjects too. By designing their vulnerability our society is actually shaping itself. The robots, through their new vulnerabilities, shape the ethical choices the human beings are called for. In addition, thanks to their different gaze, they make the human subjects naked and vulnerable in different ways.

The introduction of vulnerability into robots can be seen as a way to elevate them from mere tools and, at the same time, as a way to modify who we are.

Acknowledgements Nicola Liberati is supported by the NWO (Nederlandse Organisatie voor Wetenschappelijk Onderzoek) VICI project "Theorizing Technological Mediation: toward an empirical-philosophical theory of technology" (Grant number: 277-20-006). Shoji Nagataki is supported by Grant-in-Aid for Scientific Research (C), no. $16 \mathrm{~K} 02144$.

Open Access This article is distributed under the terms of the Creative Commons Attribution 4.0 International License (http://creativeco mmons.org/licenses/by/4.0/), which permits unrestricted use, distribution, and reproduction in any medium, provided you give appropriate credit to the original author(s) and the source, provide a link to the Creative Commons license, and indicate if changes were made.

\section{References}

Aaltonen I, Arvola A, Heikkilä P, Lammi H (2017) Hello Pepper, May I Tickle You? Children's and adults' responses to an entertainment robot at a shopping mall. In: Proceedings of the companion of the 2017 ACM/IEEE international conference on human-robot interaction, no. 6-9 March 2017. https://doi.org/10.1145/30297 98.3038362

Altez FR (2007) Banal and implied forms of violence in Levinas' phenomenological ethics. Kritike 1:52-70. http://www.kritike.org/ journal/issue_1/altez_june2007.pdf. Accessed 11 May 2018

Atterton P (2011) Levinas and our moral responsibility toward other animals. Inquiry 54(6):633-649. https://doi.org/10.1080/00201 74X.2011.628186
Becker-Asano C (2011) Affective computing combined with android science. Künstl Intell 25:245-250. https://doi.org/10.1007/s1321 8-011-0116-9

Bemelmans R, Gelderblom GJ, Jonker P, Witte L (2015) Effectiveness of robot Paro in intramural psychogeriatric care: a multicenter quasi-experimental study. J Am Med Dir Assoc 16(11):946-950. https://doi.org/10.1016/j.jamda.2015.05.0071525-8610/Ó2015

Burggraeve R (1999) Violence and the vulnerable face of the other: the vision of Emmanuel Levinas on moral evil and our responsibility. J Soc Philos 30(1):29-45. https://doi.org/10.1111/0047-2786. t01-1-00003

Butler J (2004) Precarious life: the powers of mourning. Verso, London

Butler J (2009) Frames of war. Verso, London

Cardone D, Paola P, Arcangelo M (2015) Thermal infrared imaging-based computational psychophysiology for psychometrics. Comput Math Methods Med 2015:984353. https://doi. org/10.1155/2015/984353

Coeckelbergh M (2011) Artificial companions: empathy and vulnerability mirroring in human-robot relations. Stud Ethics Law Technol. https://doi.org/10.2202/1941-6008.1126

Coeckelbergh M (2013) Human being @ risk, vol 12. In: Philosophy of engineering and technology. Springer, Dordrecht. https://doi. org/10.1007/978-94-007-6025-7

Davy BJ (2007) An other face of ethics in Levinas. Ethics Environ. http://gunkelweb.com/environment-ethics/texts/other_face_ethic s.pdf. Accessed 11 May 2018

Dolezal L (2017) Shame, vulnerability and belonging: reconsidering Sartre's account of shame. Hum Stud 40(3):421-438. https://doi. org/10.1007/s10746-017-9427-7

Dreyfus HL, Taylor C (2015) Retrieving realism. Harvard University Press, Cambridge

Duranti A (2010) Husserl, intersubjectivity and anthropology. Anthropol Theor 10(1):1-20

Foster ME, Alami R, Gestranius O, Lemon O, Niemelä M, Odobez J-M, Pandey AK (2016) The MuMMER project: engaging human-robot interaction in real-world public spaces. Springer, Cham, pp 753-763. https://doi.org/10.1007/978-3-319-47437 $-3 \_74$

Gibson JJ (1979) The ecological approach to visual perception. Houghton Mifflin Company, Boston

Guenther L (2007) Le Flair animal: Levinas and the possibility of animal friendship. PhaenEx 2(2):216-238

Habermas J (2003) The future of human nature. Polity Press, Cambridge

Hahn AC, Whitehead RD, Albrecht M, Lefevre CE, Perrett DI (2012) Hot or not? Thermal reactions to social contact. Biol Lett 8(5):864-867. https://doi.org/10.1098/rsbl.2012.0338

Hart D, Sussman RW (2005) Man the hunted: primates, predators, and human evolution. Basic Books, New York

Hermberg K (2006) Husserl's phenomenology: knowledge, objectivity and others. Continuum, New York

Husserl E (1973) Zur Phänomenologie Der Intersubjektivität. Texte Aus Dem Nachlass. Dritter Teil: 1929-1935. Edited by Iso Kern. vol. XV. Husserliana. Martinus Nijhoff, Den Haag

Husserl E (1983) Ideas pertaining to a pure phenomenology and to a phenomenological philosophy. First book. General introduction to pure phenomenology. Vol. II. Collected works. Martinus Nijhoff

Husserl E (1989) Ideas pertaining to pure phenomenology and to a phenomenological philosophy. Second book: studies in the phenomenology of constitution. Vol. III. Collected works. Kluwer Academic Publisher, Dordrecht

Ioannou S, Vittorio G, Arcangelo M (2014) Thermal Infrared Imaging in psychophysiology: potentialities and limits. Psychophysiology 51(10):951-963. https://doi.org/10.1111/psyp.12243 
Jopling D (1993) Levinas, Sartre, and understanding the other. J Br Soc Phenomenol 24 (3):214-231. https://doi.org/10.1080/00071 773.1993.11007024

Kanda T, Masahiro S, Zenta M, Hiroshi I, Norihiro H (2009) An affective guide robot in a shopping mall. In: Proceedings of the 4th ACM/IEEE international conference on human robot interaction-HRI'09. ACM Press, New York, p 173. https://doi. org/10.1145/1514095.1514127

Kruuk H (2002) Hunter and hunted: relationships between carnivores and people. Cambridge University Press, Cambridge

Kukkonen TM (2015) Devices and methods to measure female sexual arousal. Sex Med Rev 3 (4):225-244. https://doi.org/10.1002/ SMRJ.58

Kukkonen TM, Yitzchak MB, Rhonda A, Serge C (2007) Thermography as a physiological measure of sexual arousal in both men and women. J Sex Med 4(1):93-105. https://doi.org/10.111 1/j.1743-6109.2006.00399.x

Levinas E (1987) Collected philosophical papers, vol 100. In: Phaenomenologica. Springer, Dordrecht. https://doi. org/10.1007/978-94-009-4364-3

Levinas E (1988) The paradox of morality: an interview with Emmanuel Levinas. In: Bernasconi R, Wood D (eds) The provocation of Levinas: rethinking the other. Routledge, Abingdon

Liberati N (2018) Being Riajuu ['アア充]. A phenomenological analysis of sentimental relationships with "Digital Others". In: Cheok A, Levy D (eds) Love and sex with robots. LSR 2017. Lecture Notes in Computer Science, vol 10715. Springer, Cham

Lieberman D (2013) The story of the human body: evolution, health and disease. Pantheon Books, New York

Liu Z, Wu M, Cao W, Chen L, Xu J, Zhang R, Zhou M, Mao J (2017) A facial expression emotion recognition based human-robot interaction system. IEEE/CAA J Autom Sin 4(4):668-676. https://doi. org/10.1109/JAS.2017.7510622

McGee RJ, Warms RL (2013) Theory in social and cultural anthropology: an encyclopedia. SAGE Publications, Thousand Oaks

Merleau-Ponty M (1945) Phénoménologie de La Perception. Gallimard, Paris

Merleau-Ponty M (1964) Le Visible et l'invisible. Gallimard, Paris

Merleau-Ponty M (1968) Résumés de Cours: Collège de France 1952_ 1960. Gallimard, Paris
Mori M (1970) The uncanny valley. Energy 7(4):33-35

Nagataki S, Shibata M, Konno T, Hashimoto T, Ohira H (2013) Reciprocal ascription of intentions realized in robot-human interaction. In: Proceedings of the 35th annual meeting of the cognitive science society (CogSci2013), p 4005

Nortvedt P (2003) Subjectivity and vulnerability: reflections on the foundation of ethical sensibility. Nurs Philos Int J Healthc Prof 4(3):222-230. http://www.ncbi.nlm.nih.gov/pubmed/12969452. Accessed 11 May 2018

Overgaard S (2013) Wittgenstein and other minds: rethinking subjectivity and intersubjectivity with Wittgenstein, Levinas, and Husserl. Routledge, Abingdon

Sandry E (2015) Re-evaluating the form and communication of social robots. Int J Soc Robot 7(3):335-346. https://doi.org/10.1007/ s12369-014-0278-3

Sartre J-P (2001) Being and nothingness: an essay in phenomenological ontology. Citadel Press, New York

Sealey K (2013) Moments of disruption: Levinas, Sartre, and the question of transcendence. Suny Press, Albany

Shapin S (1998) The scientific revolution. University of Chicago Press, Chicago

Shildrick M (2002) Embodying the monster: encounters with the vulnerable self. SAGE Publications, Thousand Oaks

Wada K, Shibata T (2018) Robot therapy in a care house-its sociopsychological and physiological effects on the residents. In: Proceedings 2006 IEEE International Conference on Robotics and Automation, 2006. ICRA 2006, pp 3966-3971. IEEE. Accessed 6 April 2006. https://doi.org/10.1109/ROBOT.2006.1642310

Yamaji Y, Miyake T, Yoshiike Y, Okada M (2010) STB: humandependent sociable trash box. In: Proceeding of the 5th ACM/ IEEE international conference on human-robot interactionHRI' 10. ACM Press, New York. https://doi.org/10.1145/17344 54.1734541

Zahavi D (1999) Self-awareness and alterity: a phenomenological investigation. Northwestern University Press, Evanston

Zahavi D (2011) Shame and the exposed self. In: Webber J (ed) Reading Sartre: on phenomenology and existentialism. Routledge, London, pp 211-226

Zahavi D (2014) Self and other: exploring subjectivity, empathy, and shame. Oxford University Press, Oxford 